\title{
La praxiología wittgensteiniana versus el trascendentalismo kelseniano
}

Wittgensteinian praxeology versus Kelsenian transcendentalism

A praxiologia wittgensteiniana versus o transcendentalismo kelseniano

\section{MARIO GARCÍA BERGER}

Doctor en Filosofía

Universidad Autónoma de la Ciudad de México, México

Correo electrónico: mgberger@live.com 


\section{Resumen}

Este artículo argumentó en contra de las tesis de corte praxiológico (la concepción praxiológica del significado del segundo Wittgenstein [1989] sostiene que el significado de las palabras del lenguaje está en su uso) que subyacen a los intentos de extender las ideas del segundo Wittgenstein acerca del lenguaje y el significado al ámbito de la ciencia del derecho. Asimismo, se ofrecen razones a favor de la concepción "trascendental" del conocimiento postulada por Kant, refinada por el movimiento neokantiano y adoptada por Hans Kelsen. En primer lugar, se exponen algunos de los planteamientos que se han hecho con el propósito de aplicar las ideas wittgensteinianas a la ciencia jurídica. A continuación, se somete a crítica la confusión entre conocimiento y práctica del derecho en que estos planteamientos se sustentan. Como se pondrá de manifiesto, esta confusión deriva de una concepción de tipo praxiológico acerca del significado. Después se describe, en líneas generales, la epistemología del neokantismo marburgués para mostrar que ella nos da una mejor explicación del conocimiento jurídico que la que se desprende de la concepción praxiológica del significado. En suma, la conclusión es que las ideas de Wittgenstein no son aplicables a la jurisprudencia. De paso, se sugiere que quizás algunas discusiones extrajurídicas, más propias de una reflexión filosófica sobre el derecho que de su conceptualización y descripción, podrían ser objeto del tipo de análisis gramatical que encontramos en las Investigaciones filosóficas.

Palabras clave: praxiología; filosofía trascendental; neokantismo; Wittgenstein; Kelsen; ciencia jurídica; filosofía del derecho.

\section{Abstract}

This article argued against the praxeological thesis (the praxeological conception of meaning of the second Wittgenstein [1989] claims that the meaning of the words of language is in their use) that underlies the attempts to extend the ideas of the second Wittgenstein about language and meaning to the field of the science of law. Likewise, reasons are offered in favor of the "transcendental" conception of knowledge postulated by Kant, refined by the neo-Kantian movement and adopted by Hans Kelsen. First, some of the approaches that have been made with the purpose of applying Wittgensteinian ideas to legal science are exposed. Next, the confusion between knowledge and practice of the law on which these approaches are based is criticized. As it will be explained, this confusion derives from a praxeological conception of meaning. Then, a general description of the epistemology of the Marburg Neokantism is provided to show that it gives us a better explanation of legal knowledge than that which derives from the praxeological conception of 
meaning. In sum, the conclusion is that Wittgenstein's ideas are not applicable to jurisprudence. It is further suggested that perhaps some extra-legal discussions, more typical of a philosophical reflection on law than of its conceptualization and description, could be the object of the type of grammatical analysis that we find in the Philosophical investigations.

Keywords: praxeology; transcendental philosophy; neookantism; Wittgenstein; Kelsen; legal science; philosophy of law.

\section{Resumo}

Este artigo argumentou contra a tese praxiológica (a concepção praxiológica do significado do segundo Wittgenstein [1989] argumenta que o significado das palavras da linguagem está em seu uso), subjacente às tentativas de estender as ideias do segundo Wittgenstein ao respeito da linguagem e do significado ao campo da ciência do direito. Da mesma forma, são apresentadas razóes a favor da concepção "transcendental" do conhecimento postulada por Kant, refinada pelo movimento neokantiano e adotada por Hans Kelsen. Em primeiro lugar expóem-se algumas das conceiçóes que têm sido feitas com o propósito de aplicarem as ideias wittgensteinianas à ciência jurídica. Em seguida, a confusão entre conhecimento e prática do direito em que estas propostas estão sustentadas é submetido a critica. Como será evidenciado, essa confusão é originada por concepçôes de tipo praxiológico ao respeito do significado. Depois é descrito, em linhas gerais, a epistemologia do neokantismo marburgués com o proposito de mostrar que esta aproximação nos fornece uma explicação melhor do conhecimento jurídico que aquela originada da concepção praxiologica do significado. Em suma, a conclusão é que as ideias de Wittgenstein não são aplicáveis à jurisprudência. A propósito, sugerese que talvez algumas discussóes extrajudiciais, mais típicas de uma reflexão filosófica sobre o direito do que de sua conceituação e descrição poderiam ser objeto do tipo de análise gramatical que encontramos nas Investigaçōes Filosóficas.

Palavras-chave: Praxiología; filosofia transcendental; neokantismo; Wittgenstein; Kelsen; ciência jurídica, filosofia do direito. 


\section{Introducción}

Hay un grupo de filósofos del derecho que han usado la filosofía del llamado segundo Wittgenstein, en especial su concepción de los juegos del lenguaje, del significado como uso y sus aclaraciones sobre lo que es seguir una regla, para abordar temas como la naturaleza del derecho, de la interpretación jurídica y del lenguaje normativo. ${ }^{1} \mathrm{Si}$ las miramos de cerca, es posible descubrir en estas propuestas de tipo wittgensteiniano una epistemología y una filosofía del lenguaje de corte praxiológico, para las que el conocimiento y el significado de las palabras tienen su fundamento en la praxis. Para estos autores, la práctica de los agentes jurídicos determina el significado de los términos normativos. Así, si queremos saber qué es el derecho o qué es una obligación o una facultad, debemos observar cómo aplican estos conceptos los jueces, legisladores, abogados y, en general, todo aquel que toma parte en una actividad jurídica.

En oposición a esta idea, podemos situar la teoría pura del derecho de Kelsen, que tiene su sustento epistemológico en la filosofía neokantiana de la escuela de Marburgo liderada por Hermann Cohen y Paul Natorp. Esta corriente de pensamiento sostenía, según un desarrollo consecuente de la filosofía kantiana que conservaba su espíritu pero superaba sus inconsistencias, que el conocimiento era resultado de la razón pura, pues incluso la experiencia era una construcción del pensamiento.

Este artículo se propone argumentar a favor de la visión kelseniano-trascendental del conocimiento y en contra de la vertiente praxiológica que está detrás de los intentos de extender las tesis wittgensteinianas al ámbito de la ciencia del derecho. Primero, se expondrán algunos de los planteamientos que se han hecho en este sentido y se hará una crítica de la confusión entre conocimiento y práctica del derecho en que se sustentan, que deriva de la concepción praxiológica del conocimiento. Después se describirá, en sus líneas generales, la epistemología del neokantismo marburgués para mostrar que esta concepción permite una mejor comprensión de la naturaleza del conocimiento jurídico que la praxiológica. La conclusión es que las ideas de Wittgenstein acerca del significado como uso y sobre lo que es seguir una regla no son aplicables a la ciencia del derecho. Sugeriré, de paso, que quizás algunas discusiones extrajurídicas, más propias de una reflexión filosófica sobre el derecho que de su conceptualización y descripción, podrían ser objeto del tipo de análisis gramatical que encontramos en las Investigaciones filosóficas.

A este respecto puede consultarse la compilación de textos hecha por Dennis Patterson (2004b). 


\section{El panorama}

Como sabemos, entre las preocupaciones de Wittgenstein no figuró la filosofía jurídica. En sus textos, no hay reflexiones sobre el derecho o la jurisprudencia. ${ }^{2}$ Tampoco encontramos aclaraciones sobre los llamados fines del derecho: justicia, paz, resolución de conflictos, de problemas de coordinación, etc. En sus consideraciones sobre lo que es seguir una regla, los ejemplos son de reglas lingüísticas y matemáticas, pero no de normas jurídicas. Sin embargo, a pesar de que en la obra wittgensteiniana del segundo periodo no hay un análisis del juego del lenguaje jurídico, algunos autores han intentado aplicar sus aclaraciones gramaticales o su concepción lingüística general a ciertos debates en la ciencia del derecho. Estos esfuerzos tienen su punto de partida en el reconocimiento que Hart (2007, p. 315) hace de la influencia de Wittgenstein en su noción de regla de reconocimiento.

Entre los ámbitos de discusión en los que se ha echado mano de Wittgenstein, se destacan dos que están estrechamente relacionados: la determinación o indeterminación de las normas jurídicas, y la interpretación del derecho. En el primero, la distinción introducida por Hart entre casos fáciles (clear cases) y difíciles (hard cases) puso en la mesa el papel de los jueces cuando deciden asuntos en los que no es claro qué disposiciones deben aplicar. En estas circunstancias, la presencia de dos o más normas en conflicto que dan lugar a soluciones opuestas o la ausencia de reglas relevantes para el caso han generado controversias sobre la relación entre la moral y el derecho, el grado de discrecionalidad de los jueces y la conveniencia de que estos creen nuevas normas para fundamentar sus decisiones, y asuman temporalmente el rol de legisladores.

Son estos casos difíciles los que han puesto de relieve la determinación o indeterminación del lenguaje jurídico. Se afirma que, si el lenguaje natural es indeterminado, también lo es el del derecho, y los jueces tienen que interpretarlo, dotarlo de sentido antes de poder aplicarlo. En cambio, si se piensa que el lenguaje posee significados claros y distintos, la función adjudicativa consistirá en subsumir los casos particulares en reglas generales. Estos razonamientos se conciben como silogismos en los que, primero, se describe el hecho específico, luego se identifica la disposición normativa aplicable y, al final, se establece la sentencia o subsunción. Por ejemplo:

Usaré como sinónimos los términos ciencia del derecho, ciencia jurídica y jurisprudencia. 
P1: Pedro cometió un homicidio

P2: A quien cometa un homicidio se le condenará a veinte años de cárcel

C: A Pedro se le condenará a veinte años de cárcel

Tanto defensores como críticos de la tesis de la indeterminación lingüística han usado a Wittgenstein para apuntalar sus puntos de vista (Bix, 2004, pp. 406407). Quienes favorecen esta tesis y piensan que en él hay un argumento escéptico adoptan la interpretación kripkeana de las consideraciones wittgensteinianas sobre el seguimiento de reglas, según la cual no hay forma de determinar la interpretación correcta de una regla. ${ }^{3}$ En cambio, los críticos de la indeterminación rechazan que en estas consideraciones haya una posición escéptica. Un análisis cuidadoso de las secciones relevantes de las Investigaciones filosóficas muestra claramente que su idea central es que en el fondo de cualquier cadena de interpretaciones encontramos un acuerdo en formas de vida. Al final, las interpretaciones dejan su lugar a las prácticas compartidas. Como se afirma en la sección 198, una persona sigue una señalización en la medida en que existe un empleo regular, una costumbre de usar estos símbolos. Así, la normatividad, entendido este concepto en el sentido del uso correcto de un término, es posible porque compartimos una forma de vida (Wittgenstein, 1989, p. 241).

Por otro lado, las discusiones en torno a la interpretación del derecho están directamente relacionadas con la indeterminación del lenguaje jurídico. Cuanto mayor sea esta, mayor necesidad habrá de interpretar las normas. En la literatura, existen análisis de la actividad interpretativa de los jueces inspirados en la concepción de los juegos del lenguaje como prácticas sociales. Veamos ahora algunas de las conexiones que se han querido establecer entre las ideas de Wittgenstein y los debates en torno a la naturaleza del lenguaje jurídico y a la interpretación del derecho.

\section{Wittgenstein y la ciencia jurídica}

Comencemos con el rechazo de Marmor (2004) a la idea de que antes de la aplicación de cualquier norma hay siempre una interpretación. Él afirma, wittgensteinianamente, que, así como en muchos casos en el lenguaje natural no hay mediación entre comprender una palabra y aplicarla, pues el

No es este el lugar para discutir el análisis de Kripke (1991), solo mencionaré que rechazo su intepretación y que sostengo que, en Wittgenstein, no hay espacio para una posición escéptica en torno al significado del lenguaje. 
uso correcto de un término es criterio suficiente para adjudicar competencia y comprensión lingüística, de igual manera en el proceso de adjudicación no tenemos necesariamente una interpretación entre la identificación de una norma y su aplicación al caso concreto. Solo si se mostrara que las normas son siempre semánticamente inciertas, habría razones para sostener que antes de aplicarlas debemos interpretarlas. Esto se podría hacer, por ejemplo, recurriendo a hipótesis acerca de las intenciones del legislador o echando mano de principios de moralidad pública para leer las normas de manera más amplia, más allá de su sentido literal, o acorde con las convicciones prevalecientes en una sociedad. Pero si no existen motivos para suponer una situación de incertidumbre semántica generalizada, en los llamados casos fáciles se pasa directamente de la identificación-comprensión de las normas aplicables a un caso, a su subsunción en ellas. Esta comprensión es, en última instancia, producto de nuestro acuerdo fundamental en formas de vida. Afirma Marmor:

\begin{abstract}
Así, a menos que pudiera mostrarse que, debido a cierto rasgo que solo la adjudicación posee, esta requiere un procedimiento constante de traducción,. no tenemos razón para dudar de que las normas jurídicas son con frecuencia entendidas y luego aplicadas directamente, sin que medie una hipótesis sobre sus propósitos. La interpretación es necesaria solo cuando la norma deja dudas acerca de su aplicabilidad en un contexto determinado. En tales circunstancias, las presuposiciones en torno a los objetivos de las normas desempeñarían un papel prominente — quizás aun preeminente- para despejar su falta de claridad semántica. ${ }^{4}$ (p. 355)
\end{abstract}

Una visión un tanto diferente de la anterior es la de Patterson (2004), para quien los métodos o "argumentos" de interpretación de las normas son los que hacen posible el seguimiento de reglas y la existencia misma del derecho. Distingue cuatro tipos de métodos: el textual, que es el más común y consiste en tomar al pie de la letra el significado ordinario de las palabras; el histórico, empleado para reconstruir disposiciones constitucionales y acudir a los significados de los términos relevantes que sus creadores tuvieron en mente, o normas de menor rango y escudriñar los propósitos que los legisladores tuvieron al emitirlas; el método doctrinal que busca discernir los principios usados en anteriores decisiones para aplicarlos a nuevas circunstancias; y, por último, el método prudencial que se concentra en los efectos que resolver un caso en un sentido u otro tiene para el logro de ciertos propósitos colectivos (p. 36).

Las traducciones son mías. 
Estos "argumentos" proporcionan a las normas su significado o normatividad, pues permiten afirmar la corrección o incorreción, la verdad o falsedad de proposiciones normativas del tipo "En el ordenamiento mexicano existe una norma fiscal que obliga a todas las personas físicas a presentar anualmente su declaración del impuesto sobre la renta”. Al darnos las reglas del juego del lenguaje jurídico, estos métodos hacen posible las diversas prácticas jurídicas: argumentar a favor o en contra de un caso, dictar una sentencia, identificar normas, etc. Las formas de "argumentación" conforman la gramática del derecho, es decir, la base compartida e intersubjetiva de los juicios normativos.

La objetividad del derecho, señala Patterson (2004), requiere no solo que estemos de acuerdo en que estos métodos dotan a las normas de significado, sino que es crucial que los participantes en la práctica las empleen y reaccionen a su uso de la misma forma. Sin coincidencia en juicios, no habría objetividad en el derecho. La conexión de la normatividad jurídica con las formas públicas de "argumentación" explica por qué los usuarios del juego del lenguaje del derecho poseen un discurso intersubjetivo común. Así, las normas son objetivas en tanto se reconoce que tales métodos son formas legítimas de justificación culturalmente determinadas (pp. 36-38).

En el terreno de la interpretación, también hay propuestas de corte wittgensteiniano relativas a la naturaleza del derecho y de la labor de abogados y jueces. Perspectivas de este tipo son las de Thomas Eisele y Douglas Lind. El primero hace una revisión crítica de la jurisprudencia tradicional que ve en las normas objetos independientes de nosotros que requieren, para poderlas conocer, que adoptemos la misma actitud que los científicos de la naturaleza tienen con respecto a sus objetos de estudio. Para esta visión, el derecho está en el mundo para ser descrito como lo están las plantas y los mares, es decir, sin relación con nosotros hasta que decidimos investigarlo. Por ello, la descripción de las normas puede ser verificada con la misma exactitud que la de cualquier otra entidad del mundo natural (Eisele, 2004, p. 154).

Eisele (2004) piensa que la analogía del derecho con los objetos físicos es equivocada y que este debe concebirse como un arte o actividad. La mejor forma de diferenciarlos es con su modo de origen. Los objetos físicos son resultado de procesos naturales que se desenvuelven sin nuestra intervención; en cambio, las artes o las actividades humanas emergen de manera similar a los juegos que inventamos, voluntariamente y, a veces, con esfuerzo. Sus productos son artefactos cuyo lado material no es resultado de leyes causales, sino de la destreza artística 
de sus creadores. En este sentido, la elaboración de un texto legal se asemeja a la producción de arte (pp. 154-155).

Otro rasgo de los artefactos es que generan interés, incluso excitación, algo no común con los objetos físicos. Aquellos dependen de nosotros para existir y poseen tal calidad solo en tanto los consideramos así. Los textos jurídicos, Eisele (2004), comparten con ellos este modo de ser en, al menos, dos sentidos. Por un lado, ambos son especies de aseveraciones (utterances), porque, de cierta manera, se comunican con nosotros o nos hablan. Si bien los objetos (o fenómenos) físicos pueden también tener o expresar un significado, como cuando decimos que las nubes significan lluvia, no lo hacen mediante palabras, sino que los interpretamos en forma de signos de otros acontecimientos. Además, los textos legales, y en general los artefactos, no son elementos de cadenas causales que ocurren en el mundo. Por el contrario, estos forman parte de procesos intencionales, pues pretenden comunicar algo a su audiencia. Y este es el segundo aspecto de diferenciación entre los productos de las actividades humanas y los objetos físicos, que aquellos tienen una intención comunicativa. Por esto, una ley no es solo, ni principalmente, el texto físico, su soporte material, sino el mensaje que sus creadores quieren transmitirnos a través de ella (pp. 155-156).

Con esto, se quiere mostrar que la tendencia de la jurisprudencia tradicional de abordar el derecho como si fuese un objeto físico independiente de nosotros es equívoca y fuente de malentendidos. Este es inseparable de quienes lo crean y de las condiciones en las que surge, se emplea, modifica o deroga. Se trata de un arte, de una forma de vida. Entenderlo es comprender un aspecto de la vida humana misma. Así, la jurisprudencia se convierte en un tipo de autoentendimiento, de investigación de lo que somos y hacemos al vivir regulados jurídicamente. Si rompemos la relación que nos une con el derecho, perdemos lo esencial de los fenómenos jurídicos. Según Eisele (2004), esta concepción "artística" del derecho, que renuncia a verlo como un sistema de reglas, es más fiel a la manera en la que lo experimentamos y conocemos en la vida diaria (pp. 156-157).

Concebir el derecho desde el punto de vista de un sistema de reglas que dirige nuestras acciones tiene, según Eisele (2004), al menos tres problemas. Primero, este es mucho más ambiguo, equívoco e incompleto de lo que esta concepción supone. Segundo, esta concepción identifica la actividad jurídica con un modelo de juegos demasiado simple. Por último, entiende los sistemas de normas en forma de acciones atomizadas en vez de hacerlo como una actividad integrada que involucra actitudes, prácticas e instituciones (formas de vida) (p. 158). Para 
Eisele, las normas de un orden no transmiten su contenido inequívocamente o sin ambigüedades, sino de forma general y poco precisa. Al cubrir un rango de casos posibles, antes de aplicar las normas a controversias específicas, es necesario trabajarlas para encontrar soluciones legalmente aceptables. También hay un rechazo a ver los sistemas jurídicos como libros que contienen las reglas definitorias de los movimientos obligatorios, permitidos y prohibidos en el juego del derecho. Se dice que existen razones convincentes para pensar que ni las actividades humanas ni los juegos que inventamos están, en lo esencial, gobernadas por reglas. El derecho es más creativo e impredecible de lo que esta imagen sugiere. Por último, no solo es falso que todos los órdenes jurídicos estén construidos sobre el modelo de las constituciones escritas o de las leyes codificadas, pero aun si fuese cierto es dudosa la idea mecanicista de las constituciones y de los códigos que esta concepción implica (Eisele, 2004, pp. 158-159).

Eisele (2004) echa mano de la noción de comunidad retórica para oponerse a la tesis de que, en esencia, las constituciones y las leyes son documentos que enuncian normas para la acción. La verdad, se afirma, es que esta función es solo una pequeña parte de la vida de estos textos. Su papel más importante es crear y mantener una comunidad retórica en cuyo seno la comunidad misma y los individuos se reconstruyen. Así, por ejemplo, la constitución norteamericana es un documento retórico en el que se localizan temas de conversación, debate y argumentación, se asignan roles a diferentes hablantes y se establecen tiempos para discutir y acordar. En suma, el derecho, además de normas, incluye también conceptos, lenguaje, actitudes, expectativas, prácticas e instituciones. La presuposición detrás de esta concepción es que para saber qué es el derecho uno debe enfocarse en cómo hablamos de él (pp. 159-161).

Si observamos con atención el juego del lenguaje jurídico, continúa Eisele (2004), nos damos cuenta de que las normas de un orden son ininteligibles si las consideramos aisladas de su ámbito social. Para comprenderlas, necesitamos penetrar sus procesos de creación, el contexto y los casos de aplicación, así como las formas de vida en que estas adquieren sus propósitos. Pensar que las normas son el único aspecto importante del derecho es ignorar los contextos en los que adquieren significado. Son las técnicas de intepretación, inmersas en las prácticas e instituciones jurídicas, las que las dotan de normatividad. Las reglas son normativas en tanto forman parte de los procesos, los métodos, las instituciones y las tradiciones jurídicas, y son incomprensibles fuera de ellos. Eisele apunta que la normatividad depende también de las actitudes de los emisores y de los destinatarios de las normas (pp. 167 y 169). 
Por ello, para dominar un ámbito del derecho, se requiere conocer sus reglas, pero también sus propósitos y la forma en la que son usadas. La jurisprudencia tradicional suponía que entre el creador y los sujetos a la norma existía una relación unidireccional y unidimensional; en cambio, la concepción "artística" sostiene que este nexo no está dado de antemano, que se reconstituye en cada ocasión y que la normatividad jurídica depende en parte de su naturaleza (Eisele, 2004, pp. 170 y 173).

Concluye Eisele (2004) que el derecho no es independiente de los seres humanos. Sus disposiciones tienen una dimensión intencional que no poseen los objetos físicos y los fenómenos naturales. El derecho está conectado con los seres humanos y sus formas de vida. Conocer este arte es conocer a sus artistas y a sus audiencias. Al reflexionar sobre él, no solo nos preguntamos qué debo hacer, qué exigen las normas o qué está permitido, sino qué puedo hacer, qué es posible dentro del orden jurídico. Así, cuando queremos saber cómo hacer lo que deseamos, volvemos al derecho para construir formas de obtenerlo. Aquí emerge una perspectiva estética para la que el derecho es un medio artístico de expresión y comunicación, una forma de crear sentido en el mundo (Eisele, 2004, pp. 174-176). ${ }^{5}$

Un tratamiento de la labor de los jueces teóricamente afín a la concepción que acabamos de exponer es la de Lind (2004). Su idea central es que la adjudicación es una actividad que requiere destreza artística. En este sentido, una decisión judicial está justificada si cumple ciertas condiciones internas de la práctica. La habilidad para satisfacer estas exigencias se adquiere solo con el ejercicio profesional. Se trata de un conjunto de requisitos de neutralidad que constriñen la libertad de los jueces, al tiempo que delimitan un espacio para el despliegue de su capacidad creativa. Estas condiciones, orientadas a la equidad y la justicia, establecen que las resoluciones de las disputas jurídicas deben ser imparciales, coherentes y viables, además de estar sustentadas en explicaciones razonadas y fijar lineamientos para casos futuros (pp. 195-196).

Esta perspectiva, que se puede etiquetar de internalista, se opone a las de tipo externalista, para las que es posible determinar el verdadero significado de la Constitución, no solo aquello que las cortes dicen que esta quiere decir. Esto lo hacen con la ayuda de principios extrajurídicos provenientes de disciplinas como

Veáse Singer (1984) para una concepción similar de la teoría jurídica, que él llama expresiva y opuesta a una de tipo determinativo. 
la filosofía, la crítica literaria y la ciencia política. Para quienes asumen esta orientación, toda interpretación debe estar inspirada en un afán de fidelidad a la Constitución. Los principios de moralidad política que dirigen la labor interpretativa se fundan, comúnmente, en teorías de la justicia, de la democracia constitucional o de los derechos, que suelen extraerse de fuentes como el propio texto constitucional, su estructura e historia, o de otras totalmente independientes de este. A veces, a estos principios se les da un carácter a priori desligado de cualquier teoría de la interpretación, aunque en otras ocasiones se entrelazan con alguna de estas concepciones (Lind, 2004, pp. 196-198).

El contraste entre las perspectivas externalista e internalista de la práctica judicial resulta claro. Por una parte, señala Lind (2004), los que introducen principios ajenos a esta actividad se embarcan en una tarea cognoscitiva distinta de la deliberación y toma de decisiones que se da en el contexto de las disputas judiciales. Asimismo, los teóricos externalistas se orientan más a los resultados (result-oriented), a las decisiones concretas de los jueces, en tanto que los internalistas tienen mayor inclinación por la práctica (practice-oriented). Ellos sostienen que las resoluciones de los casos se justifican en la medida en la que satisfacen las condiciones de excelencia de la práctica. Los externalistas le dan un peso significativo a ciertos principios abstractos de justicia o de moralidad política, mientras que los internalistas rechazan frecuentemente estos axiomas y adoptan los significados que extraen de la labor adjudicativa. Aquellos trabajan desde un paradigma racionalista, en el que las disposiciones constitucionales tienen significados precisos accesibles mediante razonamientos deductivos que parten de tales principios. En opinión de Lind, este modelo es contrario a la práctica judicial, en la que, con la investigación empírica, el razonamiento analógico y la inducción, se dota de significado a la Constitución. Por último, para el externalismo, toda adjudicación implica una labor interpretativa. Esto también parece contradecir los hechos, pues los jueces consideran que, más que interpretar, su trabajo consiste la mayoría de las veces en aplicar la Constitución (pp. 204-205).

Lind (2004) propone tender un puente entre las dos anteriores perspectivas con la adopción de un punto de vista wittgensteiniano. La pregunta que debe responderse es si los principios de moralidad política figuran en la adjudicación constitucional. Para ello, es necesario desechar cualquier preconcepción que podamos tener y observar con detenimiento la práctica. Esta mirada cuidadosa nos revela que las consideraciones morales sí tienen un lugar relevante en esta actividad, pero las formas en las que estas aparecen están determinadas por los requerimientos internos de la práctica (p. 211). 
Lind (2004) toma el ejemplo de las disposiciones constitucionales relativas a la igual protección y al debido proceso, que tienen una clara textura abierta. En cuanto a su interpretación, la Suprema Corte de los Estados Unidos ha rechazado que su vaguedad autorice a los jueces a leerlas a la luz de sus personales concepciones morales, pero ha reconocido que el significado que ella otorga a las claúsulas de textura abierta depende en parte, con frecuencia, de consideraciones normativas. No es que la Corte apele a teorías abstractas sobre lo que exige la corrección política, sino que los jueces dirigen su investigación hacia la práctica misma de la adjudicación. Así, las reflexiones morales se aplican siempre a casos concretos, por lo que son relativas, pues se ajustan a las características de estos (p. 211).

El resultado es que cualquier contenido ético que puedan tener las disposiciones constitucionales de textura abierta deriva de consideraciones fusionadas en el proceso judicial. Este significado moral debe propiciar decisiones racionales y coherentes. Desde la perspectiva internalista, las sentencias judiciales están sujetas a una crítica procedimental para determinar la medida en la que estas se apegan a las condiciones de excelencia adjudicativa. Sin embargo, los resultados de estas decisiones no son per se correctos o incorrectos. En conclusión, para Lind (2004), la adjudicación no es, en un sentido fuerte, una tarea interpretativa, sino que más bien constituye un espacio para la aplicación de normas y principios, una forma de aprehender reglas que no es una interpretación (pp. 211, 215 y 218).

\section{Conocimiento y práctica del derecho}

Acabamos de exponer algunos ejemplos de enfoques en la teoría jurídica influidos por las reflexiones del segundo Wittgenstein. Señalaba al inicio que en ellos se mezclan, sin distinguirse, consideraciones sobre el conocimiento del derecho con otras acerca de su práctica. Veamos cómo se expresa esta confusión.

En las posturas de Patterson (2004a, 2004b), Eisele (2004) y Lind (2004) sobre la determinación o indeterminación del lenguaje jurídico y, por consiguiente, la necesidad de interpretarlo, y acerca de la forma más adecuada de caracterizar la labor de los jueces, es clara la confusión entre la ciencia y la práctica del derecho. Comencemos con la primera discusión. Aquí me parece que la posición de Marmor (2004), de que el lenguaje jurídico es por lo general determinado, es acertada, dado que en la gran mayoría de las ocasiones a los jueces no se les presentan problemas de interpretación. Así, una vez que estos identifican las normas relevantes para un caso, las aplican sin que medie un acto interpretativo. 


\section{4 | Mario García Berger \\ La praxiología wittgensteiniana versus el trascendentalismo kelseniano}

Ahora bien, en la práctica, los jueces también enfrentan casos difíciles, pero de este hecho se han extraído conclusiones inatinentes, como que el lenguaje jurídico es indeterminado. Esto es un ejemplo de lo que Wittgenstein afirmaba acerca de que los filósofos, en lugar de observar lo que sucede en los juegos del lenguaje, se dedican a elaborar hipótesis abstractas o a tomar el significado usual de las palabras y darles un sentido no avalado por ninguna actividad (Wittgenstein, 1989). El fenómeno de la interpretación puede verse, siguiendo a Kelsen (1960/2002), como un esquema de posibles lecturas de las que el juez tendrá que adoptar una. En algunos momentos, por ejemplo, se verá ante la alternativa de escoger entre una interpretación literal o una que apele a las intenciones del legislador, pero este marco de posibles lecturas no está indiscriminadamente abierto, pues no cualquier interpretación es admisible. La misma existencia de métodos interpretativos es indicativa de esta delimitación.

Los comentarios de Marmor (2004) sobre la determinación del lenguaje del derecho son resultado de la observación de la práctica jurídica. Qué tan precisos o vagos sean los términos empleados en la formulación de normas depende de circunstancias propias del ejercicio legislativo. La clase de indeterminación que se da en la práctica del derecho no es filosófica, fundada en premisas abstractas o experimentos mentales, ${ }^{6}$ sino que surge del mismo lenguaje y de los contextos en los que se emplea.

Patterson, por su parte, al hablar de los "argumentos" interpretativos, señala que estos proporcionan a las normas su significado o normatividad. Una primera acotación es que resulta un poco artificial decir que hay un método literal, pues la elección entre este supuesto método y algún otro solo se presenta cuando las normas contienen términos que, por alguna razón, nos parecen problemáticos. Imaginemos una situación en la que la norma "Todos los comerciantes deben cerrar sus negocios los domingos" generara dudas sobre su aplicación y un juez tuviera que decidir un amparo promovido contra ella por personas dedicadas a la venta de espacios publicitarios en internet. Este grupo argumentaría que, si bien en un sentido literal ellos son comerciantes ya que su actividad consiste en la venta de un servicio, una interpretación histórica apegada a las intenciones del legislador mostraría que el propósito de la disposición es promover la convivencia familiar y desincentivar su asistencia, por ejemplo, a centros comerciales. El alegato de estas personas apuntaría a que, a pesar de que su actividad es estrictamente comercial, la prohibición dominical no debe aplicárseles dado que al realizarla

Un ejemplo de indeterminación filosófica sería la tesis elaborada por Quine (1964). 
por internet no entorpecen la convivencia familiar. Quizá podrían añadir que si la norma se les impusiera se atentaría contra su intimidad, pues la única manera de hacerlo sería vigilando su actividad electrónica. Solo en circunstancias así, en las que el significado usual de un término es puesto en duda para un caso determinado, tendría sentido decir que un juez debe decidir entre una lectura fiel al texto y, por ejemplo, una de tipo histórico. Sin embargo, la mayoría de las veces es impropio hablar de un método literal, pues, como indica Marmor (2004), los jueces, por lo general, comprenden el significado usual de los términos empleados en las normas y las aplican sin plantearse si deben interpretarlas literalmente o de otra forma.

Manfiesta Patterson (2004a, 2004b) que los métodos de interpretación proporcionan a las normas su significado, objetividad y normatividad, ya que estos hacen posible la coincidencia en juicios acerca de la verdad o falsedad de las proposiciones normativas. Sin esta convergencia, se perdería la objetividad de estos juicios y la normatividad de las reglas, pues no podríamos discernir lo que estas requieren de nosotros. En suma, sin una forma de vida en común, no habría derecho.

El problema con la tesis de Patterson (2004a, 2004b) es que entremezcla afirmaciones relativas a la práctica jurídica con otras que pertenecen al terreno de la ciencia del derecho. La idea de que los métodos de interpretación dotan a las normas de significado es una observación de lo que en ocasiones sucede en la adjudicación. Los jueces recurren a estos métodos cuando hay razones para no asumir el significado usual de ciertos términos. Por ejemplo, se ha sostenido que esto pasa cuando dicho significado conduce a decisiones no acordes con las convicciones morales prevalecientes. Por otro lado, objetividad y normatividad son parte de las nociones de que se sirve la ciencia del derecho para conceptualizar su objeto de estudio, pero no tienen que ver con la interpretación de las normas. La objetividad se refiere a la descripción avalorativa del derecho, mientras que la normatividad alude al nexo, en las normas jurídicas, entre el ilícito y la sanción, con el que se establece que, si se verifica la comisión de un delito, o falta administrativa, debe aplicarse una pena (Kelsen, 1960/2002).

En la crítica que hace Eisele (2004) a la jurisprudencia tradicional, que, en su interpretación, concibe las normas a la manera de objetos físicos como entidades independientes de nosotros, también se mezclan los planos de la creación y aplicación de reglas, es decir, la práctica jurídica, y el de las presuposiciones teóricas de la ciencia del derecho. Se confunde lo que es propio de la legislación y la adjudicación, que quizá tengan algo de destreza artística, con la descripción jurídica 
del derecho. Asimismo, cuando se indica que las normas dependen de nosotros para existir, o que son parte de procesos intencionales porque nos comunican su sentido, se quiere recalcar ciertos rasgos de su proceso de creación.

La idea de que los artefactos suelen provocarnos interés o excitación es una tesis, controvertida si deseamos, acerca de la relación que tenemos con las disposiciones legales. Algo parecido sucede al caracterizar el derecho como una forma de vida. Con ello, Eisele (2004) hace alusión al lugar que este tiene en nuestras vidas. Esta observación podría enmarcarse en un enfoque antropológico, pero no dentro de una perspectiva jurídica. Con la noción de comunidad retórica, se hace hincapié en determinados fines del derecho que, se dice, derivan de su práctica. Sin embargo, aun si aceptáramos que el propósito de los sistemas jurídicos es la "reconstrucción" de la comunidad y de los individuos, el establecimiento de fines no es tarea de la jurisprudencia. Que las normas son ininteligibles aisladas de su contexto social es, al menos que se pretenda que estas deben ser interpretadas históricamente, una observación sobre la importancia de este contexto para entender su gestación. De igual manera, afirmar que el derecho nos ayuda a idear caminos para hacer lo que deseamos es resaltar su uso como herramienta para conseguirlo. En todos los casos anteriores, lo que está en juego es la relevancia sociológica, antropológica, política, práctica, moral, histórica e, incluso, estética de los sistemas normativos, pero no su comprensión jurídico-científica.

En cambio, cuando pretendemos conceptualizar y describir el derecho según las categorías de la ciencia jurídica, debemos adoptar una actitud ante las normas parecida a la que el geólogo tiene al estudiar las rocas y los minerales, que en el caso del jurista es un enfoque de su objeto de estudio libre de juicios valorativos. En su descripción, el científico del derecho no debe emplear categorías ajenas a la teoría jurídica de tipo sociológico, psicológico o incluso conceptos provenientes de las ciencias naturales. Esta tendencia al sincretismo metodológico fue denunciada por Kelsen (1960/2002) y motivó su ideal de pureza en la jurisprudencia. En suma, el derecho no es independiente de nosotros si lo consideramos desde la perspectiva de su creación o aplicación, pero sí lo es en tanto objeto de estudio de la ciencia jurídica, pues es necesario que lo abordemos con la misma neutralidad valorativa y rigor metodológico con los que el geólogo se ocupa de sus objetos.

Los criterios de excelencia de la labor adjudicativa que postula Lind (2004) tienen que ver con el llamado Estado de derecho: un Estado en el que las resoluciones judiciales son imparciales y razonadas. Generar las condiciones para alcanzar este ideal, asociado a las democracias constitucionales y liberales que se consolidaron durante el siglo XX, cae en el campo del diseño de instituciones e 
incluso de la educación, pero no en el de la ciencia jurídica. Esta nos indica lo que el derecho es, pero no lo que debe ser. Los Estados monárquicos anteriores a las democracias liberales también vivían bajo sistemas normativos, aunque no hubiera un pleno Estado de derecho, por lo que los ideales o los arreglos institucionales no definen los ordenamientos jurídicos.

\section{El significado de los conceptos jurídicos}

Quiero ahora referirme a la alternativa que está en la base tanto de mis críticas a las posiciones de los autores revisados como de estas mismas, a saber, si es la práctica o la ciencia del derecho la que establece los significados del lenguaje jurídico. Detrás de la idea, compartida al menos por Patterson (2004a, 2004b), Eisele (2004) y Lind (2004), de que una adecuada descripción de lo que hacemos cuando interpretamos normas jurídicas es fundamental para saber qué es el derecho, hay una toma de posición acerca de si es la teoría o la práctica la que establece el significado de las nociones jurídicas. Afirmar que la práctica fija el sentido de los términos legales entraña aparentemente una tesis de tipo wittgensteiniano según la cual el significado del lenguaje está en su uso, por lo que, primero, tenemos que describir lo que las personas hacen y dicen cuando emplean tales nociones para, a posteriori, llegar a una concepción de lo que es el derecho. La otra forma de proceder es a priori, partir de principios o categorías para definir qué es un orden jurídico. Se trata de dos criterios de identificación: categorías a priori versus prácticas o hechos sociales. Este es, me parece, el punto nodal de discusión.

La primera alternativa gira en torno a la idea de que las acciones humanas tienen en sí mismas un significado que no es producto de un marco conceptual, descubrible mediante su atenta observación. Si vemos el actuar de abogados, legisladores, jueces y demás participantes en el juego del lenguaje jurídico, podremos indagar qué es una norma, una sanción, una obligación o una responsabilidad. Pero ¿̇realmente nuestros actos tienen un sentido jurídico que no refiere a ningún esquema conceptual, sino que está inscrito en ellos y que cualquiera, o al menos quienes toman parte en ese juego, puede leer? ¿Tiene sentido afirmar que los hechos desnudos acarrean consigo su propia interpretación?

Me parece que esta idea es equivocada, ya que, para decirlo con Kelsen (1960/2002), entre los actos humanos qua fenómenos físicos existen relaciones causales, pero no jurídicas. Que la deliberación de una asamblea de personas pueda interpretarse como una sesión de Parlamento o que la firma de unos papeles sea la celebración de un contrato comercial depende de la existencia de normas y categorías sin las que no sería factible atribuir a estos hechos una connotación jurídica (Kelsen, 1960/2002). Por 
ello, la práctica en sí misma no puede ser el origen del significado de los conceptos. Si le preguntáramos a un legislador de orientación dworkiniana en qué consiste su función, quizá nos diría que su trabajo es crear razones exclusivas para la acción, mientras que un kelseniano vería en su tarea la imputación, a ciertos hechos, de consecuencias jurídicas. En ambos casos, la atribución de sentidos no se da en un aislamiento teórico, sino dentro de un esquema conceptual.

Por su parte, la dificultad de sostener que la teoría fija el significado del lenguaje jurídico es que no existe un único marco categorial y, al parecer, no contamos con un criterio objetivo para demostrar que alguno es superior. La puerta de escape de este supuesto callejón sin salida es la contrastación de esquemas conceptuales para elegir el de mejor desempeño explicativo. Sin duda, ello entraña una idea de ciencia, justificada por los resultados teóricos de la investigación moderna, presidida por los valores de sistematicidad, coherencia, objetividad y neutralidad. Por tanto, dado nuestro ideal de ciencia, que no tenemos razones a la vista para entrever que cambie, se debe insistir en el carácter explicativo-descriptivo, valorativamente neutro, de la ciencia del derecho.

¿Por qué señalábamos que la tesis de que la práctica fija el significado de los términos jurídicos es aparentemente de tipo wittgensteiniano? Me parece que es posible sostener que los usuarios del lenguaje natural poseen una idea de lo que significan palabras como validez, imputación, responsabilidad, obligación, etc. Esta comprensión proviene del uso común de estos términos en el habla cotidiana. Por otra parte, esas mismas palabras adquieren un sentido técnico dentro de la ciencia del derecho, que comparte ciertas notas con el significado cotidiano, pero también incorpora otras que quizá ya no sean del dominio público. Esto se explica claramente porque el origen de los juegos del lenguaje especializados no puede ser otro más que el lenguaje natural, pero es evidente de la misma manera que la jurisprudencia modifica o le añade rasgos a ese sentido original.

Así, para saber si una disposición emitida por un órgano del Estado constituye o no una norma, lo más sensato es asesorarnos con alguien que conozca el juego del lenguaje del derecho. Estos profesionales poseen una serie de conceptos marco que les permiten saber cuándo un cierto pronunciamiento constituye una norma jurídica o solo una orden emitida por una banda de asaltantes. En este segundo caso, por ejemplo, no decimos que el jefe de la pandilla esté facultado para dictar mandatos obligatorios, por lo que no estamos ante la emisión de una norma. Estos conceptos, que nos permiten atribuir juridicidad a ciertos eventos, son categorías que hacen posible la constitución del objeto de estudio de la ciencia del derecho. Por tanto, si bien desde el punto 
de vista de su génesis temporal muchas nociones que pertenecen al ámbito de la ciencia jurídica surgen del lenguaje natural, la explicación o fundamentación de su significado teórico está en la jurisprudencia. Por ello, toda práctica jurídica presupone un marco conceptual que le proporciona las categorías fundamentales para su operación. En un sentido radical, no es mediante la observación de lo que hacen los operadores jurídicos que llegamos a saber qué es el derecho, sino que es precisamente porque conocemos qué es el derecho que podemos crearlo, aplicarlo u observar cómo otros lo hacen.

\section{Praxiología versus trascendentalismo}

La idea de que es la práctica la que establece el significado de los conceptos normativos parecería tener su origen remoto en una epistemología de corte empirista, para la que el conocimiento se fundamenta en la experiencia. Aquí no entendemos por experiencia un conjunto de percepciones, sino que le damos el sentido amplio de praxis o acción. Para los empiristas clásicos, la mente era una tabla rasa. Todos sus contenidos provenían, en última instancia, de sensaciones corporales. La filosofía kantiana ofrece una vía intermedia entre el empirismo y el racionalismo. Para Kant la experiencia no es un hecho bruto sino un fenómeno que es resultado de la acción de las categorías del entendimiento, que ordenan el material proporcionado por los sentidos. Sin estas categorías no tendríamos experiencias propiamente dichas, sino solo un haz informe de percepciones. El movimiento neokantiano de la escuela de Marburgo tuvo como propósito superar las infidelidades metodológicas en que, decían sus representantes, había incurrido el mismo Kant, para purificar su teoría de aquellos elementos de corte psicologista, subjetivista e iusnaturalista que convivían en el seno de su espíritu crítico (Natorp, 1975).

Para esta corriente filosófica, la deducción del fundamento del conocimiento no podía realizarse con un método empírico, pues, a partir de nuestras sensaciones, solo podemos alcanzar, inductivamente, generalizaciones probables pero no principios a priori. Tampoco era legítimo recurrir, en esta tarea, a entidades trascendentes situadas más allá de toda experiencia posible. Solo el método trascendental era capaz de deducir, para cada área del conocimiento, su fundamento de derecho (Rechtsgrund). Así, por ejemplo, a partir de la existencia de los ordenamientos positivos e históricos, se deducen sus condiciones de posibilidad, que son un conjunto de categorías como las de norma, persona, facultad, imputación, etc. Sin ellas no sería factible hablar de derecho, ya que no podríamos concebir ningún tipo de relación jurídica. Este fundamento de derecho tiene claramente 
una función teórica: hacer posible el conocimiento de los fenómenos, por lo que no debe interpretarse en un sentido metafísico o empírico. Se trata de una mera función o supuesto del pensamiento y no de una entidad trascendente.

Cohen (1922) expresa este principio metódico con su "juicio del origen" (Urteil des Ursprungs), que significa que nada es "dado" al conocimiento si no es susceptible de ser reducido al fundamento último, es decir, si no es subsumible bajo una ley. Por ello, lo "dado" es realmente "construido". Señala Cohen (p. 101): "Nichts darf dem reinen Denken als gegeben gelten; auch das Gegebene muss es sich selbst erzeugen" (Nada puede valer como dado al pensamiento puro; también lo dado debe construirse a sí mismo). En consecuencia, lo "dado" solo puede significar un problema por resolver, una variable por despejar. En la experiencia, encontramos relaciones y variaciones entre fenómenos, y la ciencia busca en ellas lo permanente.

Si para conocer tenemos que deducir los principios que ordenan el material de cada ciencia, entonces el conocimiento es un conjunto abierto de predicaciones sintéticas a priori, que explican lo múltiple mediante su reducción a una unidad nómica o principio legal. Por esto, declara Natorp (1975, p. 25): "La ley fundamental del conocimiento es la ley de la unidad sintética, es decir, de la determinación de lo en sí indeterminable, en lo infinito determinable o de lo sensible". Sobre este punto, Rodríguez (1947), unos de los iniciadores del movimiento que en México se dedicó, durante las décadas de 1960 y 1970, a propagar las ideas de los neokantianos de Marburgo, aclara que las progresivas determinaciones en que consiste el conocimiento están siempre condicionadas por su ley fundamental. Estas, a su vez, pueden ser elementos detonantes de posteriores avances al convertirse en nuevas incógnitas que deberán ser sometidas al método de la unidad sintética.

Con la función conceptual, relacionamos los datos de la experiencia con los principios a priori que los ordenan. Por tal motivo, concluye Natorp (1975, p. 16), "forma y materia del conocimiento [...] permanecen referidas una a otra", porque lo sensible es "dado" solo en cuanto lo podemos determinar conceptualmente y, de igual manera, el concepto solo puede ser referido a la materia indeterminada. Se establece así una especie de dialéctica, porque con cada determinación conceptual del sujeto del conocimiento se plantean nuevos interrogantes que requieren una posterior determinación, por lo que "el conocimiento debe ser pensado como proceso y en verdad como proceso nunca acabado" (Natorp, 1975, p. 16). Para Cohen (1922, p. 36), "Dem Ursprung darf nichts gegeben sein" (el pensamiento es el origen donde nada está dado y a partir del que todo es construido). 
El juicio del origen establece un método de creación infinita de determinaciones. Por su parte, la ley de continuidad, que es la ley fundamental del pensamiento, permite dar cuenta de cualquier cosa a partir de la nada, unificar los diferentes elementos del pensamiento descubiertos por la lógica trascendental y, de esta forma, asegurar que todos son variaciones del mismo principio. Esto significa que el método que explica la posibilidad del conocimiento es el mismo en los distintos campos del saber humano. Si queremos dar cuenta del proceder de alguna ciencia natural, explicar un fenómeno jurídico o una manifestación artística, el método crítico exige que deduzcamos, a partir del material dado a la investigación, las categorías que explican su posibilidad, es decir, el tipo de preguntas y respuestas válidas en ese ámbito.

Para el neokantismo de Marburgo, la filosofía es esencialmente método, deducción de las categorías que explican los diferentes tipos de conocimiento. La filosofía es la ciencia fundamental, porque sin ella no serían posibles las ciencias particulares. Su labor explicativa empieza una vez que el pensamiento científico se ha consolidado, pues esta se ejerce sobre las producciones culturales del hombre. Sin embargo, desde el punto de vista lógico o de la fundamentación, la filosofía antecede a dichas manifestaciones, ya que su tarea consiste precisamente en deducir los principios de todo conocimiento. Pero, además, ella es la ciencia primera, porque su fundamento está adentro y no afuera de sí misma, y debe "asegurar la unidad de los conocimientos humanos por la demostración de un último fundamento común" (Natorp, 1974, p. 15).

Para la filosofía trascendental, el conocimiento no se fundamenta en la experiencia, sino en categorías a priori sin las que no podríamos concebir sus distintos objetos de estudio. Ella nos ofrece un cuadro más exacto, que el empirismo, de la forma en que procede el conocimiento, pues el método inductivo que este suele emplear para explicar los enunciados científicos generales es incapaz de dar cuenta del elemento a priori y universal que hay en la ciencia. En este sentido, la idea de que podemos saber en qué consiste el derecho observando la forma en que es creado y aplicado es errada, pues no se trata de una observación pura, sino que esta incorpora ya elementos teóricos, que son parte de un esquema conceptual que nos permite ver en ciertos eventos del mundo hechos jurídicos. Por esta razón, se puede afirmar que es la teoría, y no la práctica jurídica, la que fija el significado de los conceptos normativos. 


\section{Conclusiones}

La aplicación de las consideraciones del segundo Wittgenstein sobre el significado como uso a ciertos temas en la filosofía del derecho ha tenido el efecto de reforzar la confusión entre lo que es conocer el derecho y practicarlo. Tales reflexiones han conducido a la idea de que el significado de los términos normativos debe buscarse en la práctica jurídica. Contrario a esta concepción, he sostenido que dicho significado está dado por la teoría jurídica, pues los actos humanos no tienen una significación per se. Además, me parece, esta idea se sostiene sobre una interpretación equivocada de las tesis wittgensteinianas acerca de los juegos del lenguaje. Para Wittgenstein (1989), los términos del habla natural tienen, cuando se usan en las ciencias particulares, un significado técnico dado por la teoría de que se trate. Así, por ejemplo, en la física, palabras como luz y color tienen un significado que, si bien está emparentado con el que tienen para los hablantes comunes, incorpora otras notas que adquieren en el juego del lenguaje de la física. Podría señalarse que esto mismo pasa en el caso de la ciencia del derecho, donde conceptos como los de obligación, derecho y responsabilidad, entre otros, poseen un significado que, si bien tiene "semejanzas de familia" con las respectivas nociones del habla cotidiana, es fijado por la teoría. Habría que añadir que los practicantes del derecho (jueces, legisladores y abogados) hacen uso de estos significados teóricos y no los coligen a partir de su propia práctica.

$\mathrm{Al}$ inicio, afirmábamos que quizás algunas discusiones, que denominaríamos extrajurídicas por estar fuera de una teoría del derecho kelseniana y neokantiana, podrían tratarse con el análisis gramatical desarrollado en las Investigaciones filosóficas. Las controversias a las que me refiero son, por ejemplo, las relativas a los fines y a los valores del derecho. No es que los usuarios del lenguaje natural, legisladores y jueces incluidos, no se cuestionen sobre estos problemas, pero lo que sin duda solo hacen los filósofos son aquellas elaboraciones abstractas en las que, como denunciaría Wittgenstein, los términos de nuestro lenguaje adquieren significados que no tienen sustento en alguna práctica social. La intuición que quiero proponer es que quizás estas discusiones constituyen seudoproblemas que pueden ser disueltos con la terapia wittgensteiniana. Sin embargo, esta intuición solo podrá corroborarse o desecharse haciendo lo que Wittgenstein nos invita a realizar: análisis gramatical para disolver las dificultades filosóficas. 


\section{Referencias}

Bix, B. H. (2004). The application (and mis-application) of Wittgenstein's rule-following considerations to legal theory. En D. Patterson (Ed.), Wittgenstein and law. (pp. 381407). Londres, RU: Routledge.

Cohen, H. (1922). Logik der reinen Erkenntnis. Berlín, Alemania: Bruno Cassirer Verlag.

Eisele, T. D. (2004). The activity of being a lawyer: The imaginative pursuit of implications and possibilities. En D. Patterson (Ed.), Wittgenstein and law. (pp. 133-177). Londres, RU: Routledge.

Hart, H. L. A. (2007). El concepto de derecho. (G. Carrió, trad.). Buenos Aires, Argentina: Abeledo-Perrot.

Kelsen, H. (1960/2002). Teoría pura del derecho. (R. J. Vernengo, trad.). Ciudad de México, México: Porrúa.

Kripke, S. A. (1991). Wittgenstein on rules and private language: An elementary exposition. Nueva York, EE. UU.: John Wiley \& Sons.

Lind, D. (2004). Constitutional adjudication as a craft-bound excellence. En D. Patterson (Ed.), Wittgenstein and law. (pp. 179-221). Londres, RU: Routledge.

Marmor, A. (2004). No easy cases? En D. Patterson (Ed.), Wittgenstein and law. (pp. 325355). Londres, RU: Routledge.

Natorp, P. (1974). El ABC de la filosofía crítica. Ciudad de México, México: Editora Nacional.

Natorp, P. (1975). Propedéutica filosófica. Ciudad de México, México: Porrúa.

Patterson, D. (2004a). Normativity and objectivity in law. En D. Patterson (Ed.), Wittgenstein and law. (pp. 7-41). Londres, RU: Routledge.

Patterson, D. (Ed.) (2004b). Wittgenstein and law. Londres, RU: Routledge.

Quine, W. V. O. (1964). Word and object. Cambridge, EE. UU.: MIT Press.

Rodríguez, G. H. (1947). Ética y jurisprudencia. Ciudad de México, México: Secretaría de Educación Pública.

Singer, J. W. (1984). The player and the cards: Nihilism and legal theory. The Yale Law Journal, 94(1), 1-70. DOI: 10.2307/796315

Wittgenstein, L. (1989). Philosophical investigations. Oxford, RU: Basil Blackwell. 